EGU2020-4730, updated on 13 Mar 2021

https://doi.org/10.5194/egusphere-egu2020-4730

EGU General Assembly 2020

(c) Author(s) 2021. This work is distributed under

the Creative Commons Attribution 4.0 License.

\title{
Global Near-Surface Wind Speed Trends in Observation and CMIP6 Historical Simulation for 1850-2014
}

Kaiqiang Deng, Cesar Azorin-Molina, Lorenzo Minola, and Deliang Chen

Regional Climate Group, Department of Earth Sciences, University of Gothenburg, Sweden (kaiqiang.deng@gu.se)

The changes in near-surface (10-m height) wind speed have direct impacts on human society, such as utilization of wind energy, air pollution dispersion and dust storm frequency, which requires comprehensive assessment and improved understanding. Based on ground-based observations and multiple atmospheric reanalysis datasets, previous research revealed significant negative and positive trends in wind speed over land and oceans, respectively. In this study, we used Coupled Model Intercomparison Project Phase 6 (CMIP6) historical simulations to investigate the association between global mean wind speed changes and human-induced forcing. It is found that both unforced pre-industrial control run and historical natural forcing experiments failed in reproducing the observed trends in land and ocean wind speeds. However, the CMIP6 historical greenhouse gas forcing successfully simulated the increasing trend in ocean wind speed, while the CMIP6 historical aerosol forcing and experiments with land use changes seemed to have caused a decreasing trend in wind speeds over both land and ocean, suggesting that anthropogenic forcings are crucial drivers for the recent changes in global wind speed. Further attribution studies are needed to better understand wind speed variability under a warming climate. 